\title{
Marcelo Milano Falcão Vieira: síntese da trajetória de um homem generoso
}

\author{
Marcelo Milano Falcão Vieira: synthesis of the trajectory of a generous man
}

Observatório da Realidade Organizacional ${ }^{1}$

Por anos de nossas vidas Marcelo nos deu o prazer de sua convivência, a alegria da amizade fraterna e a honrosa parceria de trabalho. Agora, a muitas mãos, em homenagem à vida, celebramos uma trajetória compartilhada na construção de um trabalho coletivo pleno de generosidade. Para aqueles que o conheceram, relembramos; para os demais, diremos, em poucas páginas, o que foi a trajetória acadêmica e os compromissos intelectuais de um homem, um professor, na acepção mais honrada do oficio, comprometido com o fortalecimento da área de Estudos Organizacionais no Brasil, mas, espírito inquieto, sempre aberto a novas e divergentes perspectivas, com as quais dialogava vigorosa e frequentemente.

Marcelo formou-se em Ciências Contábeis, na Fundação Universidade do Rio Grande, em sua cidade natal; foi monitor e, antes de terminar o curso, preparou seu ingresso no Curso de Mestrado em Administração da Universidade Federal de Santa Catarina, logo no ano seguinte, em 1987. Optou pela área da Administração Pública, mas se interessou desde cedo pelos estudos organizacionais que orientaram o foco de seu tema de dissertação, no qual analisou o assentamento de Ronda Alta, tentando compreender sua configuração estrutural com base na tipologia de Rothschild-Witt, que contrapunha organizações burocráticas e coletivistas. Sua inquietude com o mundo em que vivemos já se deixava vislumbrar nesta escolha temática que apontava para o universo dos problemas organizacionais fora do universo empresarial.

Ao concluir o Curso de Mestrado, Marcelo passou a integrar o Núcleo de Análise, Planejamento e Pesquisa em Organizações (NAPPO), vinculado ao Programa de Pós-Graduação em Administração (CPGA), na UFSC, grupo de pesquisa dirigido, à época, pelo professor Clóvis Machado-da-Silva, ao lado de futuros colegas como Eloise Dellagnelo e Valéria Fonseca. Ali, com bolsa de Desenvolvimento Cientifico Regional do CNPq, Marcelo iniciou sua trajetória como pesquisador e coorientador de trabalhos de dissertação e aulas na graduação. Foi, sempre, um grande companheiro de trabalho, atestam seus parceiros de primeira hora. Sério e dedicado em suas atividades, compartilhava materiais, ideias, dúvidas, reflexões sobre os temas em estudo e as experiências profissionais que vivenciava.

Os problemas brasileiros, as lutas e dificuldades do país nortearam desde então suas escolhas em pesquisa. Ratifica-o o objeto de sua tese: as prisões no Brasil e na Escócia. Realizada no âmbito do doutorado que cursou inicialmente na Universidade de Saint Andrews, na Escócia, a convite de Stewart Clegg, e, com a mudança deste para a Austrália, finalizado na Universidade de Edimburgo, entre 1993 e 1996. Esta investigação marca a sua preocupação com o papel das organizações na construção de uma sociedade mais justa.

Texto submetido em 10 de fevereiro de 2012 e aceito para publicação em 10 de março de 2012.

1 Grupo de pesquisa interinstitucional, composto por professores e estudantes no PROPAD/UFPE; EBAPE/FGV; CPGA/UFSC; PPGA/UFRGS; FEAC/UFAL. Endereço: Escola de Administração - Universidade Federal do Rio Grande do Sul / Programa de PósGraduação em Administração; Rua Washington Luiz, 855, CEP 90010-460, Porto Alegre - RS, Brasil. Site: http://www.observat.net.br. E-mail: observatorio@observat.net.br 
Se o mestrado foi um período de descobertas acadêmicas, pessoais, afetivas, emolduradas pela bela ilha de Florianópolis, da qual se dirá eternamente apaixonado, e por uma inesperada descoberta da diversidade do Brasil por meio das trocas com os colegas oriundos das diversas regiões do país, o doutorado foi o período do estranhamento momentâneo com seu país, da desmistificação do velho mundo, e da construção de uma visão mais madura e soberana sobre si e o mundo do qual então se apropriava.

Apesar do distanciamento geográfico do Brasil, do tempo dedicado aos estudos e das descobertas de outra cultura, Marcelo mantinha assiduamente contato com seus amigos e colegas de trabalho, aos quais enviava por correio, muitas vezes, materiais que havia lido, e compartilhava ideias novas e sugestões a respeito dos projetos com os quais nos envolvíamos no Brasil. Esse sempre foi um de seus mais impressionantes traços de caráter: fosse qual fosse o momento que estivesse vivendo, nunca esquecia o outro, o momento do outro, os problemas do outro. Como muitos de nós, Marcelo voltou da Europa mais brasileiro do que quando fora e, mormente, mais envolvido com os problemas do país. E assim foi sempre, um homem a quem os problemas de seu país diziam respeito, atento aos outros, à possibilidade de contribuir, de construir e encorajar seus colegas com seu trabalho sólido, coerente e responsável.

No retorno ao Brasil, deu início à sua rica trajetória profissional na Universidade Federal de Pernambuco. Como ele mesmo rememorou:

[...] conhecia pouco o nordeste do Brasil e esta foi uma época de grande aprendizagem. Foi um período de readaptação ao Brasil, mais precisamente a uma vida de professor envolvido em inúmeras atividades. Havia que devolver ao meu país o que ele havia investido em mim tendo me envolvido a tempo completo na formação de jovens pesquisadores, na produção acadêmica e tudo para o qual era solicitado².

Voltou a seu estado natal, trabalhando na Universidade Federal do Rio Grande do Sul mas de lá retornou a Pernambuco e à UFPE nos anos seguintes. Ali, contribuiu decisivamente para a criação do curso de doutorado no Programa de Pós-graduação em Administração (PROPAD). Mas sua principal realização foi dar vida a um sonho que compartilhava com seus amigos, desde o período de permanência na UFSC: organizar pesquisadores e alunos em todos os níveis de formação para produzir conhecimento de maneira coletiva, com formato e conteúdo inovador e audacioso para a área de Administração e, podemos mesmo dizer, para a academia brasileira. Inicialmente formalizado junto ao PROPAD/UFPE, o Observatório da Realidade Organizacional ganhou vida em outros estados, em instituições como o CPGA/UFSC, EBAPE/FGV, EA/UFRGS e FEAC/UFAL, e consolidou-se como um grupo de pesquisa interinstitucional. Sem dúvida, podemos dizer que este foi o melhor "sonho sonhado" para Marcelo, como grande professor e pesquisador que sempre foi. Reunidos os amigos também pesquisadores dos tempos de Florianópolis, o grupo se ampliou com os inúmeros orientandos e também outros pesquisadores que, sem receio da pieguice, se sabem unidos por laços que ultrapassam em muito as afinidades acadêmicas.

Em 2002 foi para o Rio de Janeiro, vinculando-se à EBAPE/FGV. Ministrou cursos em todas as regiões do país e também no exterior. Transitava por diferentes instituições, mas não perdia os vínculos criados, sempre disponível para a participação em bancas, coorientações, cursos, palestras e projetos conjuntos. Vinculado afetivamente ao programa de pós-graduação que o formou e que lhe permitiu descobrir sua vocação, desenvolveu, junto com professores do CPGA/UFSC, um projeto de pesquisa sobre cultura e desenvolvimento no Brasil no âmbito do Programa Nacional de Cooperação Acadêmica da Capes, que deu suporte a intercâmbios acadêmicos entre alunos e professores das duas instituições de ensino.

Marcelo estabeleceu também fortes parcerias internacionais com pesquisadores da área de Administração, tais como os professores Andreu Solè, da École des Hautes Études Commerciales de Paris, Miguel Imas, da

${ }^{2}$ Trecho extraído de: CARVALHO, C. A.; VIEIRA, M. M. F, 2003, p. 17. 
Kingston University, Katarzyna Kosmala, da University of the West of Scotland, ambos do Reino Unido, e Diana Brydon, da University of Manitoba, no Canadá. Destas parcerias resultaram inúmeros trabalhos e trocas de experiências que, como sempre, ele compartilhou com seus colegas e estudantes do Observatório da Realidade Organizacional e das universidades com as quais mantinha laços.

Nos programas de pós-graduação em que atuou, Marcelo orientou 48 dissertações e nove teses. O tema predominante das teses orientadas era o desenvolvimento, que se entrecruzava com outros tais como autodeterminação, biotecnologia, produção científica e políticas culturais. Todos os doutores que ele formou encontram-se vinculados a órgãos públicos e/ou instituições do ensino superior. Muitos são hoje professores em instituições como a Universidade Federal Rural do Rio de Janeiro, Universidade Federal do Rio Grande do Sul, Universidade Federal de Viçosa e Escola Brasileira de Administração Pública e de Empresas, EBAPE-FGV. Outros atuam em órgãos públicos como secretarias de estado e Banco Central do Brasil.

Dos 48 mestres que Marcelo ajudou a formar, 19 continuam vinculados à educação superior e atuam em diferentes regiões do país. Os temas das dissertações são, como não poderia deixar de ser, mais díspares, mas alguns temas se destacam, como o desenvolvimento e a cultura. Os primeiros trabalhos orientados, tanto de mestrado como de doutorado, privilegiavam a análise da estrutura organizacional e de seus elementos constituintes, e neles já sobressaía o interesse pela análise das relações de poder. A partir de 2002 seus interesses teóricos voltaram-se para a teoria e a análise institucional dos campos organizacionais, particularmente o da cultura. Entretanto, muitos trabalhos por ele orientados se afastam destes focos e abordagens. Era aberto à diversidade de interesses dos orientandos e, sobretudo, cultivava enorme respeito por eles, por suas demandas acadêmicas e profissionais.

Ter estado sob a orientação de Marcelo em qualquer um dos níveis de formação foi uma experiência especial para cada um de seus orientandos. Muito além do processo acadêmico formal, Marcelo foi sempre um Mestre, na mais completa acepção da palavra. Durante a formação, um orientador presente e rigoroso para, ao final daquela etapa, apoiar a inserção de seus agora colegas nas mais prestigiadas atividades da vida acadêmica. Aprendemos com ele a fazer as transições de uma etapa a outra sem perder a curiosidade intelectual nem o respeito pelos colegas, orientandos e todos que se aproximaram, particularmente interessados na proposta do Observatório, ao qual parte significativa de seus orientandos se vinculou. Referência constante de compromisso ético, de entusiasmo, generosidade e companheirismo, Marcelo deu contribuições decisivas para a trajetória profissional de todos os que tiveram o privilégio de sua orientação.

Em certa altura, Marcelo decidiu que não bastava ser professor e pesquisador e assumiu responsabilidades nas instituições que definem as diretrizes da Administração. Assim, atuou como coordenador de área na ANPAD, organizador e coorganizador do II e do IV ENEO, em Recife e em Porto Alegre respectivamente, e em várias edições do Colóquio Internacional sobre Poder Local, evento pelo qual tinha enorme simpatia. Atualmente integrava o grupo de pesquisadores que organiza a fundação da Sociedade Brasileira de Estudos Organizacionais, reflexo de sua permanente preocupação com a área disciplinar e de seu espírito dinâmico e inconformista.

Em cada uma das diferentes facetas da trajetória acadêmica de Marcelo haveria inúmeras considerações a fazer, desde a análise de temas e categorias privilegiados, passando por sua imensa capacidade agregadora, até às diferentes iniciativas de que participou com o intuito de fortalecer e dinamizar a área. Uma delas foi a criação deste veículo em que fazemos circular este texto que, inspirados em seus princípios, escrevemos coletivamente.

A criação do periódico Cadernos EBAPE.BR se constituiu em um de seus projetos mais exitosos, não só pelo patamar a que levou esta publicação, mas, principalmente, pelo espaço que foi capaz de criar para o fortalecimento da área disciplinar da Administração e, particularmente, dos Estudos Organizacionais. A revista resultou do processo de revitalização de uma das publicações da EBAPE, que nasceu em 1954 e passou por reformulações até chegar ao momento em que Marcelo foi chamado a atualizá-la editorialmente. Era o ano de 2003 e, sobre esta experiência, Marcelo registrou: 
A tarefa solicitada não era fácil. A Ebape já publicava a Revista de Administração Pública (RAP) e, em parceria com o ISCTE, em Lisboa, a Revista Portuguesa e Brasileira de Gestão (RPBG). Por um lado, a nova revista deveria ser um periódico científico com linha editorial própria e bem distinta das já existentes na Ebape e, por outro, proporcionar à comunidade acadêmica na área de Administração no Brasil algo inovador. [...] decidimos por adotar uma linha que clara e explicitamente privilegiasse ensaios teóricos e pesquisas qualitativas, visto que à época nossa comunidade ainda estava sob forte influência positivista, quantitativa e, no que se refere especificamente aos Estudos Organizacionais, fundamentada na Teoria da Contingência Estrutural (VIEIRA, 2011).

No primeiro editorial, o entusiasmo, o compromisso, a abertura a novas e provocativas ideias, o cosmopolitismo, a generosidade. $\mathrm{O}$ anúncio de um novo periódico - eletrônico e de livre acesso - cuja prioridade tornou-se "[...] o debate de idéias próprias de autores nacionais e estrangeiros e a inovação na administração contemporânea" (VIEIRA, 2003). O primeiro número já mostrava a marca que iria acompanhar o periódico ao longo dos seis anos em que Marcelo esteve à frente do corpo editorial: a busca e a abertura a autores e trabalhos questionadores, ao rigor teórico e metodológico, à interdisciplinaridade, à análise da produção do conhecimento na área, à consolidação de uma área disciplinar enriquecida por olhares diversos, polêmicos, consistentes, inovadores de iniciantes e veteranos. Mostrava também o início de parcerias que perdurariam por muito tempo; entre elas, o apoio eficiente de Vânia Mattos, secretária executiva da revista, sempre atenta e gentil nas comunicações com autores e avaliadores, e de Leonardo Darbilly, assistente editorial que, desde a graduação até o curso de doutorado, pode vivenciar as variadas nuances do trabalho acadêmico, sob o olhar atento e o estímulo encorajador de seu orientador em todos os níveis de sua formação superior.

A excelente aceitação do periódico, comprovada pelo número de acessos ao site e de downloads de artigos, indicou a necessidade imediata de tornar sua publicação mais frequente: de semestral, passou a quadrimestral já em seu segundo ano de vida. No segundo número de 2004, o editorial expressava, enfaticamente, uma das constantes preocupações de Marcelo: a produção e a avaliação dos trabalhos acadêmico-científicos. Crítico de um modelo que privilegia a quantidade, fosse no âmbito dos programas de pós-graduação (formação de mestres e doutores), fosse no da atuação individual (publicação de artigos), Marcelo defendeu a necessidade de mudança de estratégia na área. Para ele, os resultados desta forma de produzir estavam nos transformando em "[...] partícipes de uma produção em massa, de artigos, livros e também de mestres" (VIEIRA, 2004a). E questionava:

Se é verdade que as regras não nos satisfazem, por que não alteramos os critérios de avaliação, transformando-os em critérios mais adequados para a atual realidade do campo? Quem elege os representantes da Capes ou do CNPq? Nós, acadêmicos, temos obrigação de interagir com eles de forma mais expressiva, e exigir que, ao menos, lutem para aproximar o rumo das coisas à vontade da comunidade acadêmica (VIEIRA, 2004a).

Indignado com os rigores canônicos de avaliadores desprovidos de compromisso com a formação e a qualificação de novos pesquisadores e inconformado com o conservadorismo reinante, acrescentou:

[...] não há espaço para o novo, para o criativo. [...]. Atualmente, qualquer texto que não apresente a forma padrão com cinco partes (introdução, fundamentação teórica, método, análise e conclusão, nessa ordem) e que não seja completamente isento de posicionamento do autor tem dificuldade de ser aceito em revistas ou congressos. Mesmo que o seu conteúdo, por vezes, seja bom. Isto é fruto da pasteurização na produção do conhecimento. Ora, precisamos nos posicionar mais. Temos obrigação de ter algo a dizer sem termos que ser panfletários. Afinal, estamos tratando aqui de ciência social. Aplicada, sim, mas sobretudo SOCIAL (VIEIRA, 2004a). 
Coerente com seu compromisso de fortalecimento da área, a crítica aos critérios de avaliação não se tornaram justificativas para fugir dos rigores deste processo. Ao final de seu segundo ano de existência, Cadernos EBAPE.BR foi inserido no Sistema Qualis de avaliação de periódicos. E Marcelo voltava à carga, reafirmando os objetivos do periódico:

Quero deixar aqui explícita a disposição deste periódico em aceitar sem "pré-conceitos" trabalhos que fujam aos ditames do dogmatismo positivista, que isenta o pesquisador de responsabilidade sobre seu trabalho. Acredito que, por trabalharmos com uma ciência social [...] como a Administração, e ainda mais, em um país que está longe de ser um exemplo de sociedade justa, não podemos nos dedicar a simples reprodução de modelos gerados e legitimados nos centros mundiais de produção do conhecimento sem uma avaliação crítica a respeito dos efeitos de sua aplicabilidade na nossa realidade (VIEIRA, 2004b).

Além disso, considerava imprescindível inserir a produção brasileira no contexto internacional. Em 2005, Marcelo anunciava a versão em inglês do site de Cadernos EBAPE.BR e, em 2006, a versão em espanhol. Ampliava-se a possibilidade de interesse e de alcance dos trabalhos publicados no periódico e reafirmava-se a aposta na qualidade de nossa produção acadêmico-científica. Ainda em 2005, o periódico tornou-se trimestral, sinal indubitável de consolidação de um projeto editorial fruto de um posicionamento coerente, criativo e inovador.

Números especiais temáticos, coletâneas de trabalhos premiados em eventos, registros de programas importantes para a qualificação do ensino, editorias especiais, criação de novas seções reafirmavam a disposição para fomentar o diálogo como instrumento poderoso de fortalecimento da área, seja por meio de consensos ou disputas, pensamentos convergentes ou polêmicos. O horizonte era sempre o da troca, do esforço em proporcionar debates relevantes para a área e para a sociedade.

A constante preocupação com nossa produção acadêmico-científica e seu forte embasamento teórico fizeram Marcelo questionar categorias importantes de teorias muito difundidas. Questionando a noção de contexto de referência como baliza para a qualificação na produção de conhecimento, Marcelo apontava o risco da legitimação do mimetismo. Afirmava ele:

Reproduzimos, apesar de toda a nossa tradição, o que é dado como legítimo por quem domina o campo (os países centrais, nomeadamente, EUA e países europeus). Ao reproduzirmos não inovamos. Ao imitarmos seremos sempre jogadores de reserva ou, talvez, até mesmo a bola no jogo e não jogadores (VIEIRA, 2006a).

A temática é reafirmada no editorial seguinte, agora centrando a discussão sobre a tão desejada e discutida internacionalização de nossa produção. Mais uma vez, recusando o mimetismo ou a subordinação intelectual, Marcelo provocava:

Por que os estudiosos da CEPAL ganharam relevância internacional? Por que os autores da tradição crítica brasileira são sempre reverenciados? Certamente não por reproduzirem conhecimento, nem tampouco estruturas acadêmicas copiadas dos países dominantes. Ora, elas servem a eles, não a nós. Eles ganharam importância ao pensar a América Latina e o Brasil com a cabeça e o corpo nesses lugares. O que se observa hoje é que o corpo de grande parte de nossos pesquisadores na área de Administração parece estar no lugar, mas a cabeça nos EUA ou na Europa (VIEIRA, 2006b).

Com a coragem que lhe permitiu confrontar velhas noções que permeiam as editorias de periódicos de nossa área - como a fixação pela internacionalização a qualquer custo, pela criação de marcas isoladas em sites individuais, pela aversão ao novo e pela perenidade na função -, Marcelo contribuiu decisivamente para que Cadernos EBAPE.BR alcançasse, em 2007, o conceito A Nacional, segundo os critérios vigentes à época, do 
Comitê de Avaliação de Periódicos da Capes/Qualis, traduzidos atualmente para o conceito B1. Conduziu também o processo de inserção do periódico na biblioteca eletrônica SciELO, o mais importante portal de periódicos científicos brasileiros. Em 2009, afastou-se da função de editor do periódico que criou e que se tornou, no período de seis anos, um dos veículos mais importantes na disseminação de "[...] reflexões de pesquisadores, ensaístas, estudiosos que de alguma forma constroem o pensamento crítico da nossa realidade" (VIEIRA, 2009). Concluída a transição de editoria, no último número de 2009, ficou registrado:

Reiteramos a missão dos Cadernos EBAPE de promover debates em diferentes âmbitos da administração pública e de empresas, por meio de abordagem editorial fundamentada na interdisciplinaridade e na reflexão crítica, particularmente comprometidos com o desenvolvimento teórico-conceitual da área de Administração no (e a partir do) Brasil (GUEDES e VIEIRA, 2009).

Com o entusiasmo, a coerência, a coragem, a curiosidade e a permanente disposição para o diálogo que marcaram a trajetória de Marcelo, sua atuação como editor de Cadernos EBAPE.BR não poderia ser diferente: competente, criativa, generosa, dedicada. Cabe a nós, pesquisadores da área, e ao grupo editorial que dá sequência a este projeto honrar este trabalho e renová-lo permanentemente, ancorados nos princípios que o fundaram.

Mas foi no Observatório o melhor "sonho sonhado", como dissemos antes, que Marcelo realizou o trabalho que mais o encantou e que considerou sua melhor obra. Esta teve início em longos debates, madrugadas adentro, nos idos do curso de mestrado em Florianópolis, quando discutíamos a forma de potencializar a atividade de investigação de professores e estudantes nas universidades públicas. No Observatório, o trabalho coletivo, compartilhado, que sempre se continuava nas pesquisas uns dos outros, ao aprofundar ou questionar as reflexões anteriores, imprimia o ritmo e o caráter das relações. Marcelo demonstrava uma natural e genuína capacidade de equacionar a construção cotidiana do trabalho coletivo combinada com a reflexão e o questionamento individual, solitário, necessário ao amadurecimento de ideias. Esse amadurecimento, sempre compartilhado, imbuído da generosidade que o caracterizou, tornava fácil o trabalho coletivo ainda que em um universo de crescente competitividade. Para nós, era fácil trabalhar com Marcelo; ele sabia receber e compartilhar. Duas outras características estavam sempre presentes em todas as relações que estabelecia: respeito e confiança. O respeito por si e pelos colegas e a confiança neles o tornaram um grande ouvinte. Marcelo ouvia e considerava as diferenças como matéria para reflexão - muitas vezes, e muito naturalmente, para fortalecer seu próprio ponto de vista, mas, muitas outras, para refletir e se transformar. Quando assim era, ele prontamente reconhecia e, com outra característica marcante, gentilmente ligava para dizer que tinha usado determinada ideia ou refletido sobre sua colocação. A acirrada competitividade e exigente produtividade do nosso universo acadêmico nunca foram capazes de afetar a generosidade e a fraterna troca intelectual, sempre pontuada com um especial tato para expressar suas críticas.

Muito presente está ainda a dor da perda, mas ela se ameniza com a satisfação e o orgulho de podermos dizer, neste espaço livre de debate acadêmico que ele iniciou, quem foi Marcelo Milano Falcão Vieira, um professor e pesquisador com quem tivemos o inesquecível privilégio de compartilhar o prazer de viver e contribuir para a construção de um pensamento engajado na área dos Estudos Organizacionais.

Aqui ficamos neste breve depoimento. Aqui continuamos o que com ele começamos.

- dor não é amargura.

(Adélia Prado) 


\section{Referências}

CARVALHO, C. A.; VIEIRA, M. M. F. Apresentação. In: CARVALHO, C. A.; VIEIRA, M. M. F. (Orgs.).

Organizações, cultura e desenvolvimento local: a agenda de pesquisa do Observatório da Realidade Organizacional. Recife: Ed. Universitária UFPE, 2003. p. 17-20.

GUEDES, A. L.; VIEIRA, M. M. F. Editorial. Cad. EBAPE.BR, v. 7, n. 4, dez. 2009. Disponível em: http://app.ebape.fgv.br/cadernosebape/asp/dsp_editorial.asp?coded=76. Acesso em: 29 jan. 2012.

VIEIRA, M. M. F. Editorial. Cad. EBAPE.BR, v. 1, n. 1, ago., 2003. Disponível em: http://app.ebape.fgv.br/cadernosebape/asp/dsp_editorial.asp?coded=1. Acesso em: 25 jan. 2012.

VIEIRA, M. M. F. Editorial. Cad. EBAPE.BR, v. 2, n. 2, jul., 2004. Disponível em: http://app.ebape.fgv.br/cadernosebape/asp/dsp_editorial.asp?coded=7. Acesso em: 25 jan. 2012.

VIEIRA, M. M. F. Editorial. Cad. EBAPE.BR, v. 2, n. 3, dez., 2004. Disponível em: http://app.ebape.fgv.br/cadernosebape/asp/dsp_editorial.asp?coded=8. Acesso em: 26 jan. 2012.

VIEIRA, M. M. F. Editorial. Cad. EBAPE.BR, v.4, n.2, jun., 2006. Disponível em: http://app.ebape.fgv.br/cadernosebape/asp/dsp_editorial.asp?coded=41. Acesso em: 26 jan. 2012.

VIEIRA, M. M. F. Editorial. Cad. EBAPE.BR, v.4, n.3, out., 2006. Disponível em: http://app.ebape.fgv.br/cadernosebape/asp/dsp_editorial.asp?coded=42. Acesso em: 26 jan. 2012.

VIEIRA, M. M. F. Editorial. Cad. EBAPE.BR, v.7, n.2, jun., 2009. Disponível em: http://app.ebape.fgv.br/cadernosebape/asp/dsp_editorial.asp?coded=72. Acesso em: 28 jan. 2012.

VIEIRA, M. M. F. Sobre a revista: histórico. Cad. EBAPE.BR, 2011. Disponível em: http://app.ebape.fgv.br/cadernosebape/asp/dsp_sobre_revista_historico.asp. Acesso em: 28 jan. 2012. 